\title{
GERMINAÇÃO DE SEMENTES DE CAFÉ (Coffea arabica L.) SUBMETIDAS A DIFERENTES CONCENTRAÇÕES E TEMPOS DE EMBEBIÇÃO EM CELULASE ${ }^{1}$
}

\author{
JULIANA DE FÁTIMA SALES ${ }^{2}$ \\ AMAURI ALVES DE ALVARENGA ${ }^{3}$ \\ JOÃO ALMIR DE OLIVEIRA ${ }^{4}$ \\ FRANCISCO DIAS NOGUEIRA ${ }^{5}$ \\ LÚCIO COSTA REZENDE ${ }^{6}$ \\ FABIANO GUIMARÃES SILVA ${ }^{7}$
}

\begin{abstract}
RESUMO - As sementes de café germinam lentamente em razão de a semeadura ser feita logo após a colheita, o que coincide com o período frio do ano, e também por causa de o pergaminho constituir uma barreira que dificulta a absorção de água pela semente. Objetivando avaliar o efeito da aplicação exógena da enzima celulase sobre a germinação de sementes de café, foi realizado o experimento com sementes de café, cultivar Acaiá
\end{abstract}

do Cerrado, imersas em solução de celulase em diferentes concentrações $\left(0 ; 1,6 ; 3,2\right.$ e 6,4 g.L $\mathrm{L}^{-1}$ em tampão citrato de potássio $0,05 \mathrm{M}$ e $\mathrm{pH} 4,8$ ), por 0,72 e 144 horas. Observou-se que a enzima celulase na concentração de 6,4 g.L. L $^{-1}$ proporcionou maior índice de velocidade de germinação (IVG) e porcentagem de germinação, quando as sementes ficam em contato com a solução por 144 horas.

TERMOS PARA INDEXAÇÃO: Coffea arabica L., enzima, celulase, germinação.

\section{COFFEE (Coffea arabica L.) SEEDS GERMINATION AFTER TREATMENT WITH DIFFERENT CONCENTRATIONS AND EMBEBDING TIMES IN CELLULASE}

\begin{abstract}
The seeds of coffee trees germinate slowly, because the seeding is done soon after the crop is harvested, what coincides with the cold period of the year, and also due to the parchment, which constitutes a barrier that hinders the absorption of water for the seed. Aiming to evaluate the effect of exogen application of cellulase enzyme to coffee seed germination, an experiment was performed soaking
\end{abstract}

coffee seeds, cultivar "Acaiá do Cerrado", in cellulase solution at different concentrations $(0,1.6,3.2$, and 6.4, $\mathrm{g} \mathrm{L}^{-1}$ ) in $0.05 \mathrm{M} \mathrm{K}$-citrate buffer at $\mathrm{pH} 4.8$ for 0,72 , and 144 hours. It was found that the cellulase enzyme at the concentration of $6.4 \mathrm{~g} \mathrm{~L}^{-1}$ provided the greatest index of speed germination and the greatest germination percentage when the seeds remained in contact with the solution for 144 hours.

INDEX TERMS: Coffea arabica L.; enzyme, cellulase, germination.

\footnotetext{
1. Parte do trabalho de dissertação da primeira autora para a obtenção do título de Mestre em Agronomia/Fisiologia Vegetal.

2. Bióloga, M.Sc. Fisiologia Vegetal - UNIVERSIDADE FEDERAL DE LAVRAS/UFLA, Caixa Postal 37 - 37200-000 - Lavras, MG.

3. Professor Doutor do Departamento de Biologia/UFLA.

4. Professor Doutor - Departamento de Agricultura/UFLA.

5. Pesquisador Doutor - UFLA/EPAMIG.

6. Estudante do curso de Agronomia e Bolsista de Iniciação Científica/UFLA.

7. MSc., Doutorando em Fitotecnia - Departamento de Agricultura/UFLA.
} 


\section{INTRODUÇÃO}

A propagação predominante do cafeeiro é feita por meio de mudas oriundas de sementes que apresentam problemas para conservação prolongada, sendo a semeadura feita logo após a colheita das sementes, o que coincide com o período frio do ano, tornando a germinação lenta e irregular. Esse fato tem sido uma das maiores preocupações dos produtores de sementes, uma vez que essas não conservam o seu poder germinativo em níveis satisfatórios por períodos superiores a seis meses após a colheita. Diante desse fato, a obtenção de mudas, muitas vezes, fica concentrada em épocas que nem sempre são as mais apropriadas para o plantio (Pertel, 2001).

Portanto, a época de plantio da lavoura cafeeira tem sido extremamente dependente da época de colheita, tendo em vista que as sementes armazenadas não apresentam qualidade fisiológica satisfatória no momento ideal para a formação das mudas. A possibilidade de obtenção de sementes de alta qualidade, em qualquer época do ano, oferece ao produtor a oportunidade de programar a instalação de sua lavoura na melhor época para sua região e, conseqüentemente, formar lavouras mais precoces e produtivas. Nesse sentido, tratamentos pré-germinativos que utilizam meios com restrição hídrica ou embebição direta das sementes em água têm sido uma alternativa visando a uma germinação mais rápida e uniforme (Guimarães, 2000).

A germinação da semente é considerada a retomada do crescimento do eixo embrionário, o qual se encontra paralisado nas fases finais do processo de maturação, mas estimulado por condições ambientais, desenvolve-se, ocorrendo, então, o rompimento do tegumento pela radícula. É uma etapa crítica do biociclo vegetal, pelo fato de esse processo estar associado a vários fatores de natureza extrínseca, como os fatores ambientais, e intrínseca, ou seja, a processos fisiometabólicos (Popinigis, 1977; Labouriau, 1983; Andrade \& Damião-Filho, 1989; Bianchetti, 1991; Borges \& Rena, 1993; Bewley \& Black, 1994; Santos, 1999).

De acordo com Marcondes et al. (1983), a celulose é um componente básico da parede celular e um dos compostos mais abundantes na natureza. É um composto constituído de resíduos de glicose unidos por ligações glicosídicas do tipo $\beta-1,4$. Na maioria das vezes, em sementes de café, ela se encontra associada a polissacarídeos, como hemicelulose, pectina, e também associada à lignina, o que dificulta sua degradação. A hidrólise da celulose pode ser realizada por meio de tratamentos ácidos ou básicos e, ainda, por ação de enzimas celulolíticas produzidas pela flora microbiana, como fungos Trichoderma viride, Trichoderma reesei (Marcondes et al., 1983), por Aspergilus sp, pela bactéria ruminal celulolítica Clostridium cellobioparum e, ainda, possivelmente por outros organismos, como térmitas ou cupins (Howard \& Elliotti, 1988).

Howard \& Elliotti (1988), nesse sentido, observaram que sementes de Euonymus americanus tratadas com fluido ruminal contendo Clostridium cellobioparum tiveram sua germinação aumentada substancialmente, pelo fato de esse microrganismo sintetizar endocelulase, o que favoreceu a embebição e, conseqüentemente, a germinação das sementes.

Sales (2002), estudando a germinação das sementes de café, verificou que a hidrólise do pergaminho dessas sementes "in vitro" é diretamente proporcional à concentração e ao tempo de exposição à solução de celulase. A celulase na concentração de 1,6 g.L $\mathrm{L}^{-1}$ não proporcionou aumento na velocidade de germinação das sementes.

Com ste trabalho objetivou-se verificar o efeito da aplicação exógena da enzima celulase em diferentes concentrações sobre a porcentagem e velocidade de germinação das sementes de café.

\section{MATERIAL E MÉTODOS}

O experimento foi conduzido no Laboratório de Análise de Sementes do Departamento de Agricultura/Setor de Sementes da Universidade Federal de Lavras, no ano de 2001, utilizando-se sementes de café da cultivar Acaiá do Cerrado colhidas na fazenda experimental da EPAMIG, no município de Lavras, MG.

Sementes com pergaminho foram embebidas em soluções com diferentes concentrações de celulase de Aspergillus niger $\left(0 ; 1,6 ; 3,2\right.$ e 6,4 g. $\left.\mathrm{L}^{-1}\right)$ preparadas em becker contendo tampão citrato de potássio $0,05 \mathrm{M}$ a $\mathrm{pH} 4,8$. Os tratamentos de pré-embebição variaram de 0,72 e 144 horas.As sementes não foram lavadas após a imersão em solução de celulase. Foram utilizadas 200 sementes por tratamento, sendo 4 repetições com 50 sementes. Durante o período de imersão, as sementes foram mantidas em câmara tipo BOD, numa temperatura constante de $30{ }^{\circ} \mathrm{C}$, sob luz contínua e aeração constante. Após cada período de imersão, amostras de parte das sementes tratadas foram colocadas para germinar em rolos de papel tipo "germitest" umedecidos com água destilada, na quantidade de 2,5 vezes o peso 
do papel, e mantidas em germinador tipo "Mangelsdorf" sob temperatura de $30^{\circ} \mathrm{C}$.

As avaliações dos testes de germinação foram realizadas por meio de contagens diárias, computando-se o número de sementes que apresentavam início de protrusão da radícula para a determinação do IVG (índice de velocidade de germinação), que foi calculado segundo a fórmula de Maguire (1962), em que:

$\mathrm{IVG}=\mathrm{G}_{1} / \mathrm{D}_{1}+\mathrm{G}_{2} / \mathrm{D}_{2}+\ldots \mathrm{G}_{\mathrm{n}} / \mathrm{D}_{\mathrm{n}}$

Em que:

IVG= Índice de Velocidade de Germinação

$\mathrm{G}_{1}, \mathrm{G}_{2}, \ldots, \mathrm{G}_{\mathrm{n}}=\mathrm{n}^{\mathrm{o}}$ de radículas emergidas, observadas no intervalo da $1^{\mathrm{a}}, 2^{\mathrm{a}}, \ldots$, última contagem;

$\mathrm{D}_{1}, \mathrm{D}_{2}, \ldots, \mathrm{D}_{\mathrm{n}}=\mathrm{n}^{\mathrm{o}}$ de dias de semeadura à $1^{\mathrm{a}}, 2^{\mathrm{a}}, \ldots$, última contagem.

A porcentagem de germinação foi obtida após 60 dias de semeadura, computando-se o número de plântulas normais obtidas, segundo as regras para análise de sementes (Brasil, 1992). Outra parte das sementes foi transferida para bandejas plásticas contendo uma mistura de terra e areia em proporções iguais, a fim de determinar o IVE (índice de velocidade de emergência) e a porcentagem de emergência (plântulas normais). O número de plântulas emergidas, considerando quando os cotilédones se desprenderam do solo. O IVE também foi calculado de acordo com a fórmula de Maguirre (1962), e a porcentagem de emergência (plântulas normais), após completa estabilização do estande, foi finalizada aproximadamente aos 80 dias de semeadura.

O experimento foi constituído de esquema fatorial $4 \times 3$, sendo 4 concentrações da enzima e 3 tempos de imersão. O delineamento utilizado foi em blocos ao acaso, utilizando-se 4 repetições com 50 sementes cada uma. O teste de média utilizado foi o de Tukey, a $5 \%$ de probabilidade.

\section{RESULTADOS E DISCUSSÃO}

As sementes imersas por 144 horas apresentaram melhores porcentagens de germinação, enquanto aquelas imersas por 0 e 72 horas, não diferiram estatisticamente entre si (Figura 1). Resultados semelhantes foram encontrados por Howard \& Elliott (1988), que verificaram aumento na porcentagem de germinação de sementes de Euonymus americanus quando houve maior tempo de contato entre sementes e enzima. Provavelmente, o menor tempo de contato das sementes de cafeeiro com a solução enzimática não tenha sido suficiente para a enzima degradar suficientemente o pergaminho da semente e permitir que a germinação ocorresse mais rapidamente.

As sementes que foram imersas em solução enzimática apresentaram índice de velocidade de germinação superiores quando comparadas com aquelas imersas somente em água. Na concentração mais elevada $\left(6,4\right.$ g. $\left.\mathrm{L}^{-1}\right)$ e no maior tempo de embebição (144 horas), as sementes apresentaram maior índice de velocidade de germinação (IVG) do que nas menores concentrações testadas, que não diferiram entre si, demonstrando ser necessário maior tempo de contato das sementes com a solução enzimática (Figura 2).

Quando se analisou o efeito das diversas concentrações de celulase sobre os diferentes tempos de imersão, foi verificado que celulase, em qualquer uma das concentrações estudadas, apresentou efeito positivo na porcentagem de sementes germinadas. Entre essas concentrações, 6,4 g.L. ${ }^{-1}$ foi estatisticamente superior às demais, 1,6 e 3,2 g.L $\mathrm{L}^{-1}$, que não diferiram entre si (Figura 2). Os resultados obtidos para IVG, em 144 horas de imersão em celulase, foi encontrado um efeito positivo na porcentagem de germinação, quando comparado com a imersão em água. Entre as concentrações de celulase estudadas, sementes imersas na concentração de 6,4 g. $\mathrm{L}^{-1}$ apresentaram resultados superiores, atingindo $52 \%$ de germinação, e as sementes imersas em concentrações mais baixas apresentaram resultados inferiores, porém não diferentes entre si, 31,5 e $24,0 \%$ para 1,6 e 3,2 g.L $L^{-1}$, respectivamente (Figura 1).

Pelos resultados apresentados na Figura 3, a porcentagem de emergência diferiu significativamente entre os tratametos avaliados. Esses resultados, provavelmente, se devem à ação dos microrganismos presentes no substrato (solo), que aceleraram o processo de degradação do pergaminho das sementes, conforme descrito por Guimarães (1995).

O tempo de imersão de 144 horas, quando utilizou celulase na concentração de 1,6 g. $\mathrm{L}^{-1}$, apresentou um menor índice de velocidade de emergência, comparado com outros tempos e soluções de imersão analisados, que pela lentidão do processo germinativo, o tempo mais prolongado provavelmente pode ter proporcionado um efeito de "priming" ou condicionamento fisiológico (Figura 4). 


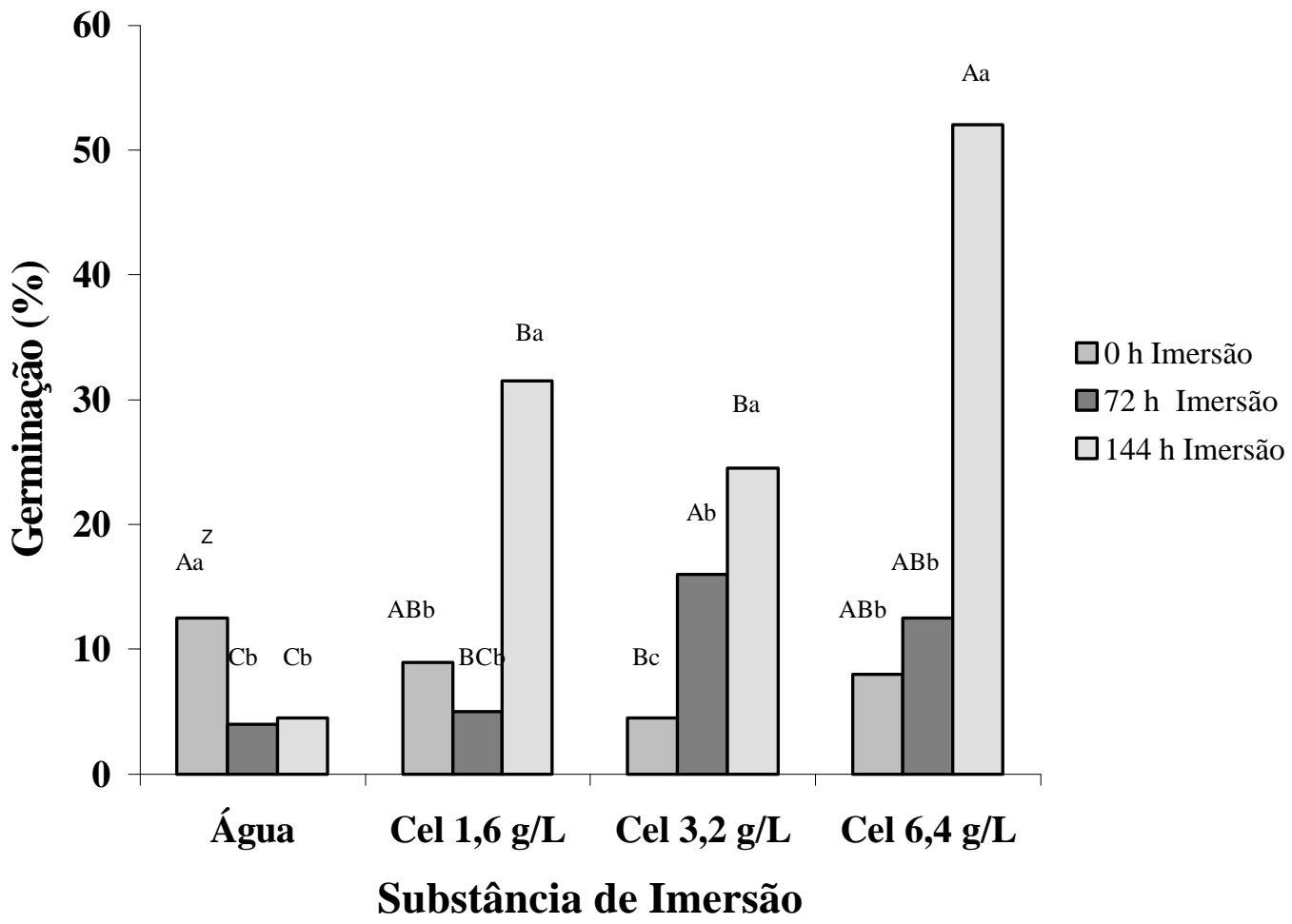

FIGURA 1 - Porcentagem da germinação de sementes de cafeeiro submetidas à imersão em soluções com diferentes concentrações de celulase por diversos tempos. ${ }^{\mathrm{Z}}$ Médias seguidas pela mesma letra maiúscula entre os tempos de imersão dentro de cada substância e minúsculas entre substâncias dentro de cada tempo de imersão não diferem entre si pelo teste de Tukey a $5 \%$ de probabilidade. 


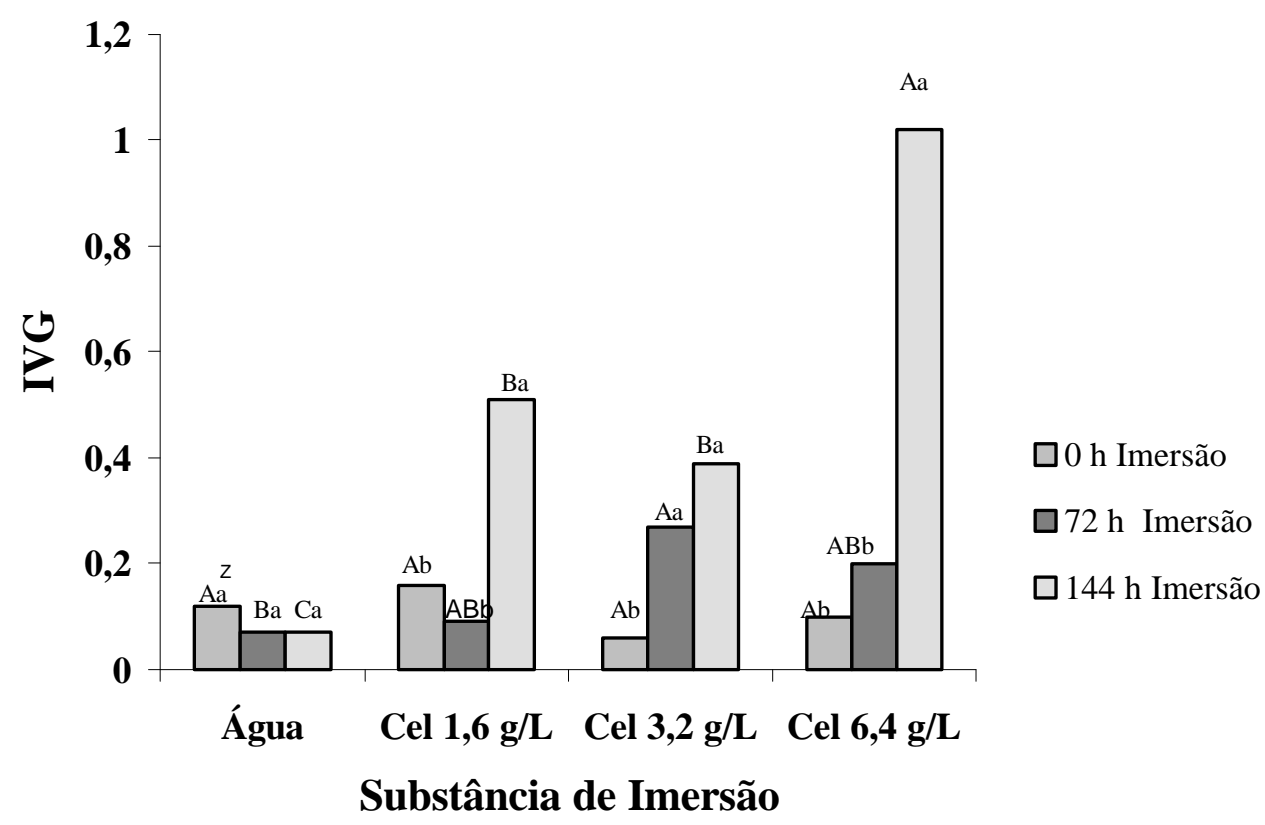

FIGURA 2 - Índice de velocidade de germinação (IVG) de sementes de cafeeiro submetidas à imersão em soluções com diferentes concentrações de celulase por diversos tempos. ${ }^{\mathrm{Z}}$ Médias seguidas pela mesma letra maiúscula entre os tempos de imersão dentro de cada concentração e minúsculas entre as concentrações dentro de cada tempo de imersão não diferem entre si pelo teste de Tukey a 5\% de probabilidade. 


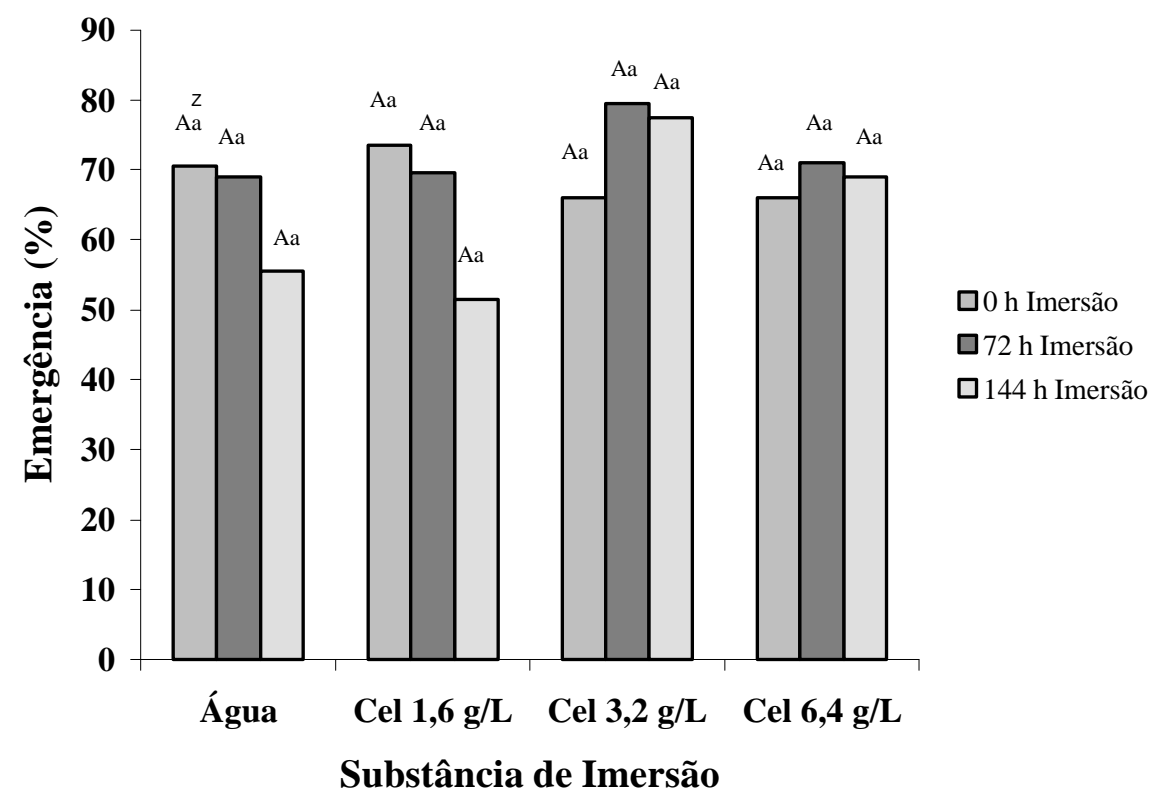

FIGURA 3 - Porcentagem de emergência de sementes de cafeeiro submetidas à imersão em soluções com diferentes concentrações de celulase por diversos tempos. ${ }^{\mathrm{Z}}$ Médias seguidas pela mesma letra maiúscula entre tempos de imersão dentro de cada substância e minúsculas entre substâncias dentro de cada tempo de imersão não diferem entre si pelo teste de Tukey a $5 \%$ de probabilidade. 


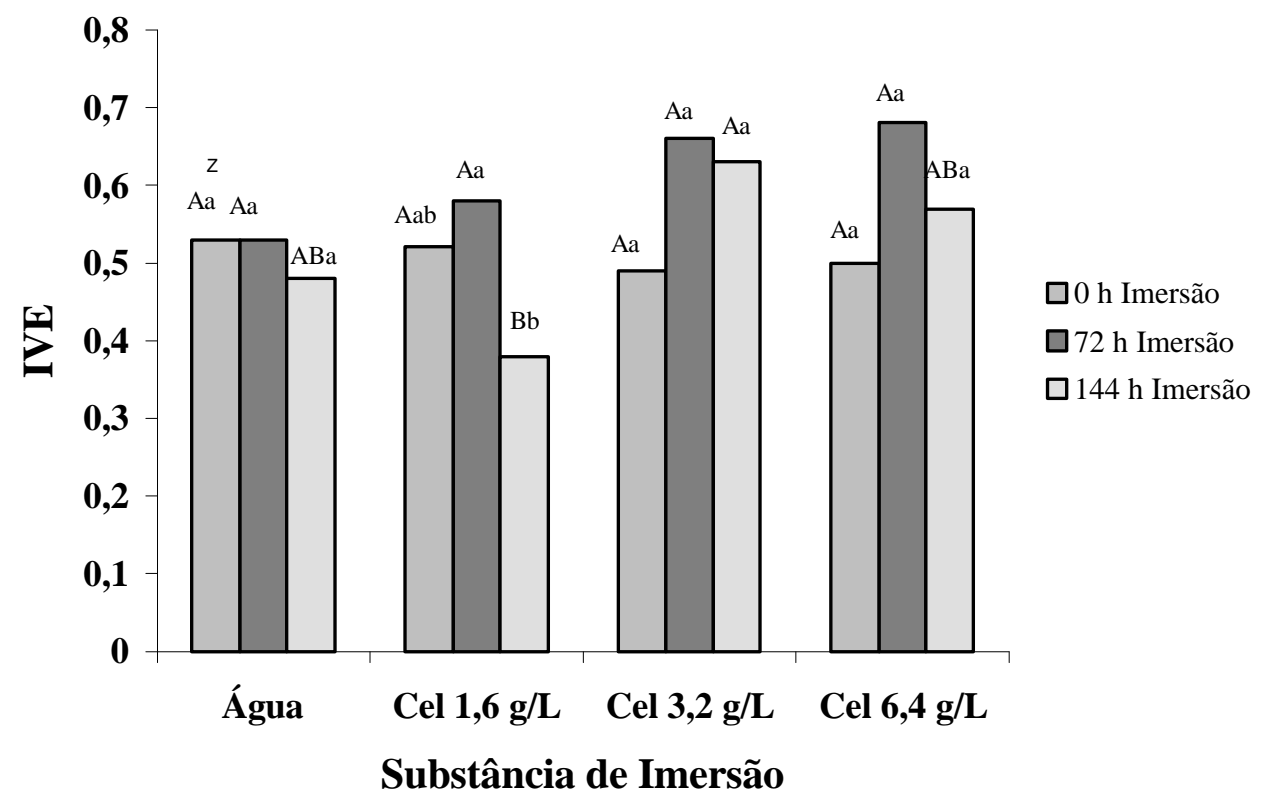

FIGURA 4 - Índice de velocidade de emergência (IVE) de sementes de cafeeiro submetidas à imersão em soluções com diferentes concentrações de celulase por diversos tempos. ${ }^{\mathrm{Z}}$ Médias seguidas pela mesma letra maiúscula entre tempos de imersão dentro de cada substância e minúsculas entre soluções dentro de cada tempo de imersão não diferem entre si pelo teste de Tukey a $5 \%$ de probabilidade.

\section{CONCLUSÕES}

a) Para os parâmetros analisados, IVG e porcentagem de germinação, o tratamento enzimático foi eficiente.

b) A enzima celulase, na concentração de 6,4 g.L $\mathrm{L}^{-1}$, proporcionou maior índice de velocidade de germinação (IVG) e porcentagem de germinação, quando as sementes ficaram em contato com a solução por 144 horas.

c) Os experimentos demonstraram que a celulase, embora proporcione melhora na germinação das sementes de cafeeiro, ainda não proporcionou ganho representativo na emergência.

\section{REFERÊNCIAS BIBLIOGRÁFICAS}

ANDRADE, V. M. M.; DAMIÃO-FILHO, C. F. Morfologia vegetal. Jaboticabal: FUNEP/UNESP, 1989. 259 p.

BEWLEY, J. D.; BLACK, M. Seeds: physiology of development and germination. 2. ed. New York: Plenum, 1994. $445 \mathrm{p}$.
BIANCHETTI, A. Tratamentos pré-germinativos para sementes florestais. In: SIMPÓSIO BRASILEIRO SOBRE TECNOLOGIA DE SEMENTES FLORESTAIS, 2., 1989, Atibaia. Anais... São Paulo: Instituto Florestal, 1991. p. 237-246.

BORGES, E. E. L.; RENA, A. B. Germinação de sementes. In: AGUIAR, I. B.; PIÑA-RODRIGUES, F. C. M.; FIGLIOLA, M. B. (Coords.). Sementes florestais tropicais. Brasília: ABRATES, 1993. p. 83-135.

BRASIL. Ministério da Agricultura. Regras para análise de sementes. Brasília: DNPV-DISEM, 1992. $365 \mathrm{p}$.

GUIMARÃES, R. J. Análise do crescimento e da quantificação de nutrientes em mudas de cafeeiro (Coffea arabica L.) durante seus estádios de desenvolvimento em substrato padrão. 1995. 113 f. Dissertação (Mestrado em Fitotecnia) - Escola Superior de Agricultura de Lavras, Lavras. 
GUIMARÃES, R. M. Tolerância à dessecação e condicionamento fisiológico em sementes de cafeeiro: (Coffea arabica L.). 2000. 180 p. Tese (Doutorado em Fitotecnia) - Universidade Federal de Lavras, Lavras.

HOWARD, G. T.; ELLIOTTI, L. P. Effects of cellulolytic ruminal bacteria and of cell extracts on germination of Euonymus americanus L. Seeds. Applied and Environmental Microbiology, Washington, v. 54, n. 1, p. 218-224, Jan. 1988.

LABOURIAU, L. G. A germinação da semente. Washington: Secretaria Geral da OEA, 1983. 173 p.

MAGUIRRE, J. D. Speed of germination aid in selection and evaluation for seedling and vigour. Crop Science, Madison, v. 2, n. 2, p. 176-177, Mar./Apr. 1962.

MARCONDES, D. M. S. S. V.; SILVA, D. M.; VITTI, L. S. S.; SILVA, J. C. Celulase do extrato de Rúmen Bovino. Energia Nuclear e Agricultura, Piracicaba, v. 5, n. 2, p. 145-160, jul./dez. 1983.
PERTEL, J. Efeito do condicionamento fisiológico na germinação, no vigor e nas alterações enzimáticas em sementes de café (Coffea arabica L.). 2001. 101 f. Dissertação (Mestrado em Fitotecnia) - Universidade Federal de Viçosa, Viçosa.

POPINIGIS, F. Fisiologia da semente. Brasília: AGIPLAN, 1997. 289 p.

SALES, J. F. Atividade da celulase sobre o processo germinativo de sementes de cafeeiro (Coffea arabica L.). 2002. 113 p. Dissertação (Mestrado em Fisiologia) - Universidade Federal de Lavras, Lavras.

SANTOS, S. R. G. dos. Efeito da temperatura na germinação de sementes de Sebastiania commersoniana (Baill.) Smith e Downs (Branquilho). 1999. 76 p. Dissertação (Mestrado em Agronomia/Produção e Tecnologia de Sementes) - Universidade Estadual de São Paulo, Jaboticabal. 